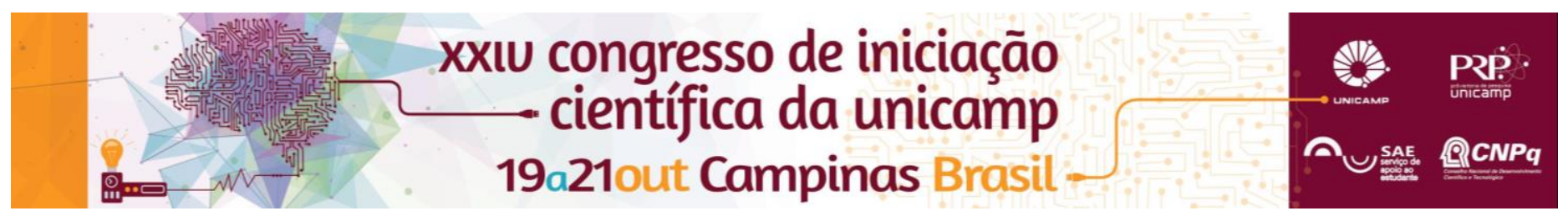

\title{
Implementação do cálculo de uma matriz de coocorrência 3D para aplicação em imagens de ressonância magnética
}

\author{
João P. O. P. Santos*, Gabriela Castellano
}

\begin{abstract}
Resumo
A matriz de coocorrência é uma ferramenta de análise de imagens que permite observar sutilezas imperceptíveis em uma análise visual. Geralmente, ela é calculada em cortes 2D, mas muitas imagens médicas, como as de ressonância magnética, são 3D. Nesses casos, são calculadas MCOs para fatias 2D da imagem 3D, ignorando as relações entre pixels de diferentes fatias. O objetivo deste trabalho foi implementar o cálculo de uma MCO em 3D, assim como das métricas que podem ser extraídas da mesma.
\end{abstract}

\section{Palavras-chave:}

matriz de coocorrência, 3D, parâmetros de textura.

\section{Introdução}

A matriz de coocorrência (MCO), também conhecida como histograma de $2^{\mathrm{a}}$ ordem, é uma ferramenta de análise de imagens que permite observar sutilezas imperceptíveis em uma análise visual ${ }^{[1]}$. A MCO relaciona o valor de cinza de um pixel da imagem com os valores de seus vizinhos e quantas vezes essa relação ocorre. A partir da MCO podem ser extraídos parâmetros estatísticos (parâmetros de textura), que permitem caracterizar a textura da imagem, e em alguns casos podem ser usados para indicar uma patologia em imagens médicas Geralmente, a MCO é calculada em cortes 2D, mas muitas imagens médicas, como as de ressonância magnética $(\mathrm{RM})$, são 3D. Nesses casos, são calculadas MCOs para fatias $2 D$ da imagem $3 D$, ignorando as relações entre pixels de diferentes fatias. A partir das MCOs 2D, são calculados os parâmetros de textura, e depois é feita uma média destes entre as fatias. Este trabalho teve como objetivo a implementação de um cálculo 3D da MCO, para aplicação em imagens de RM. Este cálculo poderia representar de uma forma melhor o que se está medindo, e devolver valores mais precisos de parâmetros de textura.

\section{Resultados e Discussão}

Para poder comparar com métodos para cálculo da MCO e seus parâmetros já existentes como o MaZda ${ }^{[2]}$, primeiro implementou-se a MCO em 2D, assim como o cálculo de seus parâmetros, usando Matlab. Este cálculo foi aplicado a uma imagem teste de RM, e verificou-se que produzia os mesmos resultados do MaZda. Em seguida, foi feita a implementação em 3D da MCO. Para isso, ao invés de considerar os 8 vizinhos possíveis de um voxel que se têm em 2D, foram considerados os 26 vizinhos possíveis que se têm em 3D. Como o Matlab indexa os valores de uma matriz em um array 1D na ordem colunas->linhas->fatias, definiu-se um método capaz de encontrar e calcular exatamente aonde estão os vizinhos de um elemento com base na quantidade de linhas, colunas e fatias. Considerando que a MCO é muitas vezes calculada para uma região de interesse (ROI) da imagem e não para a imagem inteira, também se implementou esse cálculo considerando uma máscara de segmentação, que em prática zera todos os valores indesejados de uma imagem e torna visível somente o que se deseja. No programa, mostrado na Figura 1, apenas a área segmentada é percorrida para os cálculos da MCO, e, portanto, todos os valores nulos indesejados são devidamente ignorados. O programa também calcula os parâmetros de textura a partir da MCO 3D.

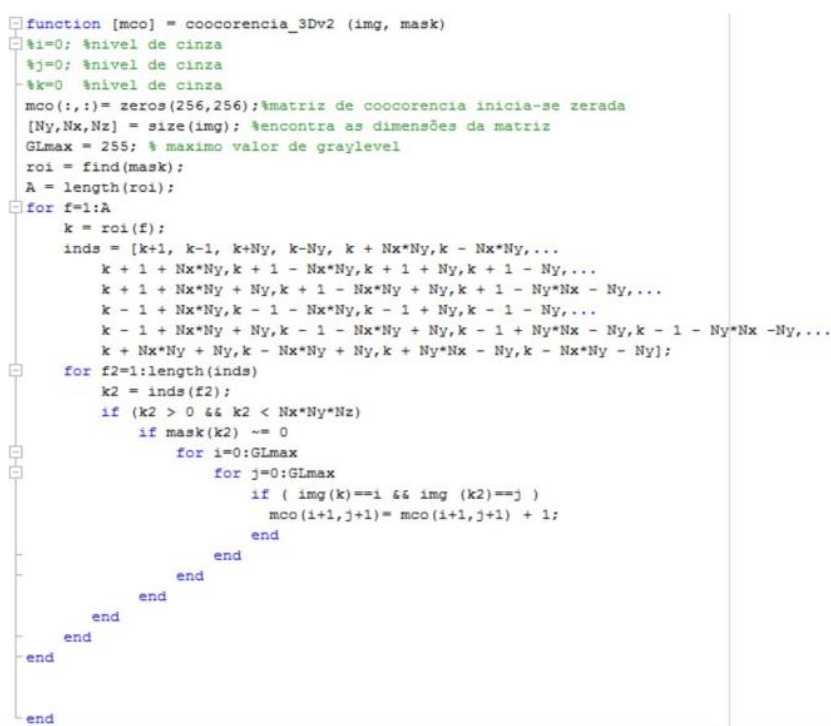

Figura 1. Programa criado para calcular a MCO em 3D.

\section{Conclusões}

Através do programa desenvolvido, foi possível encontrar a MCO de forma 3D para um hipocampo numa imagem cerebral de RM de um paciente, e os valores dos parâmetros de textura extraídos da mesma possuem a mesma ordem de grandeza dos obtidos em 2D. Futuramente, espera-se fazer este cálculo para um grupo de indivíduos sadios e um grupo de pacientes com lúpus eritematoso sistêmico (LES), a fim de verificar se há diferenças entre os valores de textura dos tecidos sadios e os patológicos. Nesse caso, a técnica desenvolvida (MCO 3D) poderá ser aplicada para o estudo do LES.

\section{Agradecimentos}

Agradecemos à FAPESP pelo apoio financeiro; e à Unicamp pelo apoio institucional.

\footnotetext{
${ }^{1}$ Haralick, R.; Shanmungam, K.; Dinstein, I. IEEE Trans. Syst., Man, Cybern. 1973, 3(6), 610-612.

2 Szczypiński, P. M.; Strzelecki, M.; Materka, A.; Klepaczko, A. Comp. Med. Activity 2009, 65, 73-84.
} 